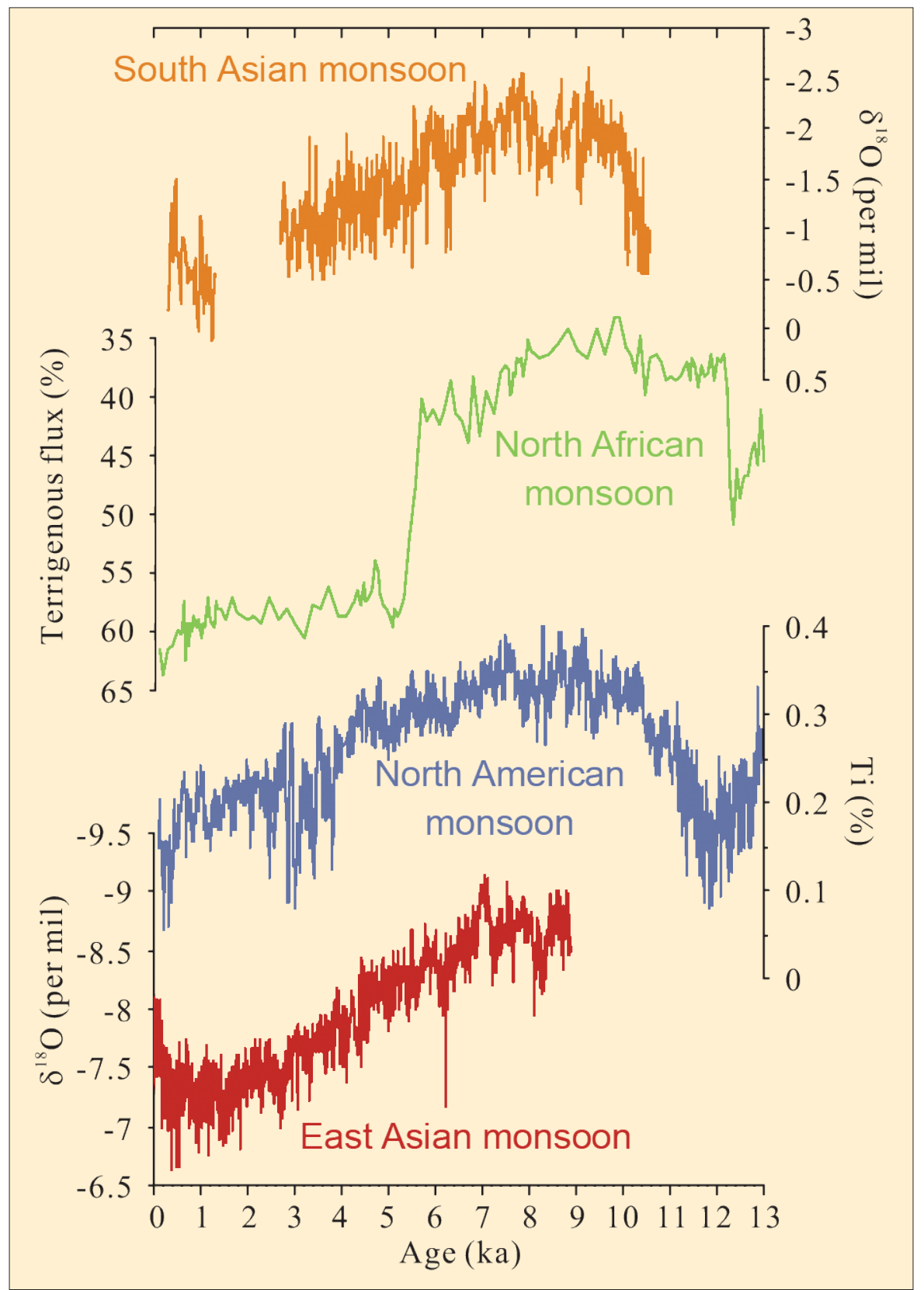

al sub-systems over a range of timescales from interannual to orbital.

\title{
References
}

deMenocal, P.B., Ortiz, J., Guilderson, T., Adkins, J., Sarnthein, M., Baker, L. and Yarusinski, M., 2000: Abrupt onset and termination of the African Humid Period: Rapid climate response to gradual insolation forcing, Quaternary Science Reviews, 19: 347-361.

Fleitmann, D., Burns, S.J., Mudelsee, M., Neff, U., Kramers, J., Mangini, A. and Matter, A., 2003: Holocene Forcing of the Indian Monsoon recorded in a stalagmite from Southern Oman, Science, 300: 1737-1739.

Wang, B. and Ding, Q., 2006: Changes in global monsoon precipitation over the past 56 years, Geophysical Research Letters, 33: L06711.

Wang, B. and Ding, 0., 2008: Global monsoon: Dominant mode of annual variation in the tropics, Dynamics of Atmospheres and Oceans, 44: 165-183.

Wang, Y. et al., 2008: Millennial- and orbital-scale changes in the East Asian monsoon over the past 224,000 years, Nature, 451: 10901093

For full references please consult:

www.pages-igbp.org/products/newsletters/ref2009_2.htm

Figure 2: Global monsoon in the Holocene: The common trend in monsoon variations in the Northern Hemisphere. A) South Asian monsoon: Stalagmite $\delta^{18} \mathrm{O}$ from Qunf Cave in Southern Oman (Fleitmann et al., 2003); B) North African monsoon: Terrigenous detritus \% from ODP 658, tropical Atlantic off Western Africa (deMenocal et al., 2000); C) North American monsoon: Ti\% in laminated deposits from the Cariaco Basin off Venezuela (Haug et al., 2001); D) East Asian monsoon: Stalagmite $\delta^{18} \mathrm{O}$ from Dongge Cave, South China (Y. Wang et al., 2005).

\section{First international cave monitoring field workshop}

\section{Gibraltar, 26 February - 1 March, 2009}

David MATteY ${ }^{1}$ AND ChRISTOPH SPÖTL ${ }^{2}$

'Department of Earth Sciences, Royal Holloway, University of London, UK; mattey@es.rhul.ac.uk 2Institute for Geology and Paleontology, University of Innsbruck, Austria; christoph.spoetl@uibk.ac.at

Cave deposits (speleothems) are one of the most promising fields in paleoenvironmental research and recent studies have highlighted the potential of this terrestrial archive to provide paleoclimatic information on a range of timescales (e.g., seasonal to orbital) (see PAGES News, 16(3), 2008). While the accuracy and the precision of uranium-thorium chronologies of speleothems are superior to many other climate-proxy dating techniques, much has still to be learned about the way climate signals are being transmitted through the soil zone and karst aquifer to be recorded in growing stalagmites or flowstone. The key to a better process understanding-enabling the eventual calibration of climate-proxy transfer functions-are long-term observations of the relationship between weather and the chain of processes that transmit the climate signal to the speleothem. Setting up and maintaining cave monitoring programs can be a challenge given that caves may be diffi- cult to access or located in remote regions. Several groups have now been involved in cave monitoring over recent years and have acquired considerable expertise but little of this knowledge has found its way into the international literature.

A 4-day workshop held in Gibraltar was convened to bring together for the first time the international researchers who are actively involved in monitoring caves around the world. The aim of this meeting was to share experience and 
discuss technical issues of cave monitoring in order to improve understanding of the local processes affecting speleothem growth and the ways that climate is recorded. The workshop was attended by 30 participants from Great Britain, Germany, Austria, Switzerland, Sweden, Spain, France, the Netherlands, Romania, and the United States, ranging from $\mathrm{PhD}$ students to university professors. The workshop, sponsored by the Gibraltar Ornithological and Natural History Society, also had local support from members of the Gibraltar Cave Science Unit (GCSU) who have been collaborating in a cave monitoring program with Royal Holloway (London) for the last five years. The workshop was held in the historic Garrison Library located at the foot of the world-famous rock, which also hosts a remarkable series of solution cave systems.

The workshop format was designed to be informal and encourage interactive

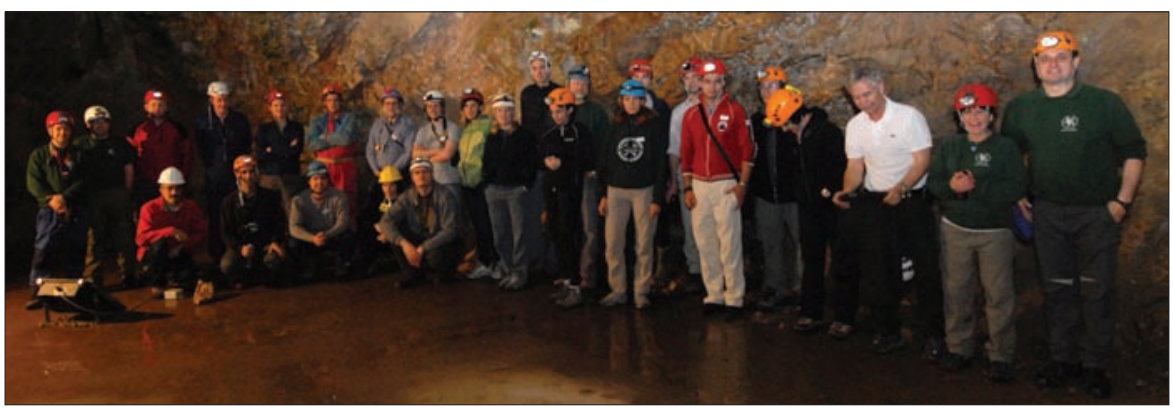

Figure 1: Workshop participants inside the rock of Gibraltar (St. Michaels Cave)

discussion. Participants contributed material for leaders to arrange into four themed sessions: Aquifer processes and climatedripwater relations (led by lan Fairchild and Dominique Genty); Karst $\mathrm{CO}_{2}$ systems and ventilation controls (led by Christoph Spötl and James Baldini); Speleothem selection, growth kinetics and sampling strategies (led by Eric James), and Data logging, automation and telemetry (led by David Mattey and Marc Luetscher). Tim Atkinson presented a stimulating introduc- tory historical perspective on cave monitoring, which was followed by discussion sessions interspersed with field visits to the cave monitoring laboratory in St. Michaels Cave (Fig. 1) and to Ragged Staff Cave, a unique site and the target of a new monitoring campaign by Royal Holloway and the GCSU beginning later this year.

Further information about the workshop and Gibraltar Cave Science can be found at www.gibcaving.net.

\section{Integrated analysis of interglacial climate dynamics - INTERDYNAMIC Status Seminar}

\section{Bremen, Germany, 24-25 February 2009}

Michael Schulz and André Paul

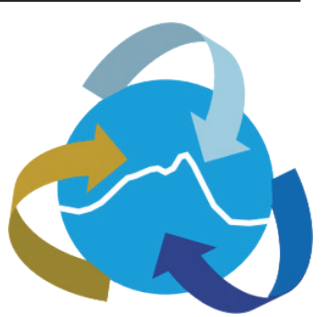

MARUM - Center for Marine Environmental Sciences and Faculty of Geosciences, University of Bremen, Germany; mschulz@uni-bremen.de

The Priority Research Program "Integrated analysis of interglacial climate dynamics" (INTERDYNAMIC), funded by the German Research Foundation (DFG), aims at a better understanding of climate dynamics using quantitative paleoclimate analyses with a view to create more reliable scenarios for future climate change.

INTERDYNAMIC is based on an integrated approach in paleoclimate research in which all available paleoclimate archives (terrestrial and marine, as well as ice cores) are combined in order to yield a comprehensive and quantitative analysis of global environmental variations. Through close linkage between paleoclimate reconstructions and results from Earth System models, detailed insights into the dynamics of climate variations are gained.

The investigations in INTERDYNAMIC focus on the interglacials of the late Quaternary (including their onset and end) and address the following key questions: - What are the amplitudes of natural climate variations on timescales of several years to millennia, and how do patterns of climate variability vary in time and space?

Do abrupt changes in the large-scale circulation of the Atlantic Ocean occur in interglacials?
- Which biogeochemical feedback mechanisms control the natural limits of atmospheric concentrations of greenhouse gases and aerosols?

- What linkages exist between climate and pre-industrial cultures?

INTERDYNAMIC was established in 2007 and has an expected duration of 6 years. The program consists exclusively of collaborative projects, in which at least two of the research fields (e.g., ice cores, marine archives, terrestrial archives and Earth System modeling) are represented. Cur- rently 13 projects are active, supporting 22 doctoral and 8 postdoctoral scientists. Information on the individual projects can be found at www.interdynamik.de

During the annual status seminar, initial results from each project were presented and discussed. Climate changes during the Holocene were addressed with respect to the hydrology of the Arctic Ocean, variation of precipitation, and flood dynamics in central Europe and central Asia. High-frequency intra-Holocene changes in the Caribbean and with respect to dust

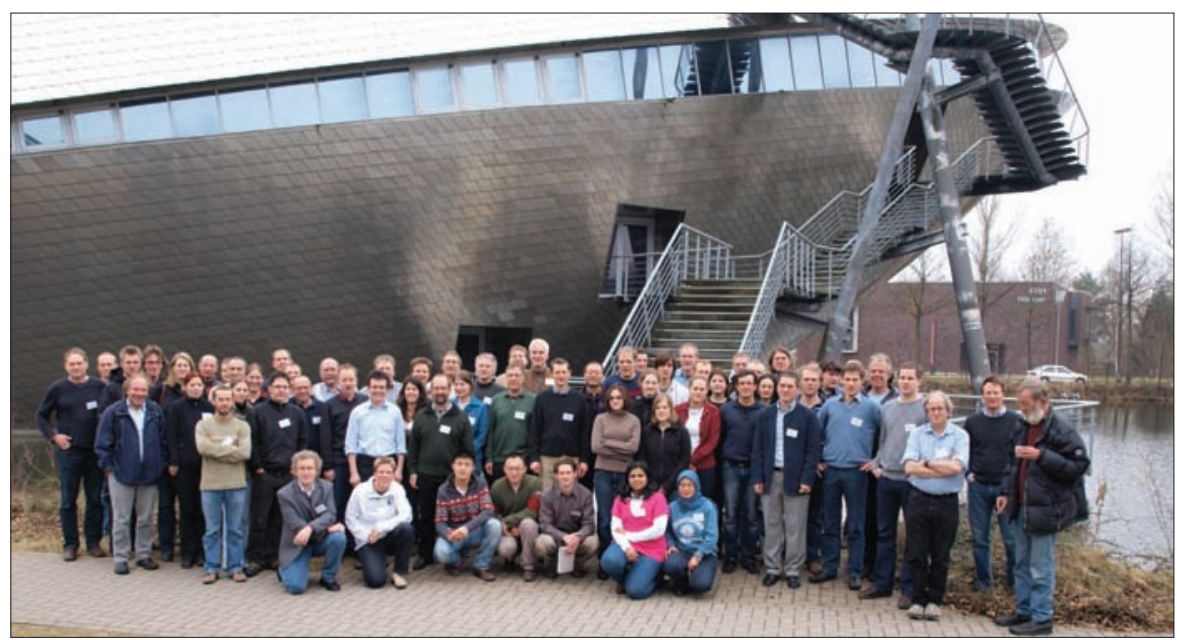

Figure 1: Participants of the INTERDYNAMIC status seminar in Bremen. 